\title{
Electrophysiological studies in acute organophosphate poisoning
}

\author{
R S WADIA, S CHITRA, R B AMIN, R S KIWALKAR, H V SARDESAI \\ From the Neurology Clinic Sassoon General Hospitals and Ruby Hall Clinic, Pune, India
}

SUMMARY Electrophysiological studies in suicidal patients with organophosphate poisoning are reported. Patients often developed muscular weakness of variable severity owing to diplorisation block at nicotinic receptors. During such paralysis nerve conduction velocity and distal latencies were normal even in severely paralysed patients. The amplitude of the compound action potential was smaller than in controls and often showed a repetitive response. The amplitude tended to be lower in those more severely affected. On repetitive stimulation there was usually no decrement with three stimuli per second and only occasional decrement at 10 per second. At $30 \mathrm{~Hz}$ several cases showed a decrement even in the absence of paralysis. This response to repetitive stimuli is thus quite distinct from that seen in either myasthenia or Eaton Lambert syndrome. On three occasions after poisoning with dichlorovos there was first anticholinesterase insecticide poisoning and later delayed neurotoxicity as seen with triorthocresylphosphate. These cases showed all the features of a severe pure motor axonal degeneration neuropathy.

Organosphosphate insecticide poisoning is the commonest mode of suicidal poisoning in India today. ${ }^{1}$ The drug is usually ingested and the patients are commonly admitted with miosis, fasciculations, pulmonary oedema and froth at the mouth due to the muscarinic, nicotinic and central manifestations of cholinergic poisoning. We have described before the neurological manifestations seen in 200 consecutive cases. ${ }^{2}$ We divided the signs into Type $I$, that is, those present on admission and responding promptly to atropine therapy and Type II as those appearing sometime after commencement of treatment and basically not influenced by atropine. Type I signs are believed to be cholinergic effects at muscarinic receptors and include bilateral pyramidal signs and impairment of consciousness and miosis. Type II are believed to be due to acetylcholine excess at nicotinic receptors. Type II paralysis appears from 12-72 hours after poisoning and lasts up to 5-6 days. This Type II paralysis is clearly different from delayed neurotoxicity, which appears only after 8-12 days and lasts much longer. ${ }^{3}$ Delayed neurotoxicity after a prior episode of clinical organophosphate anticholinesterase poisoning is furthermore very uncom-

Address for reprint requests: Dr R S Wadia, Poona Medical Foundation, Ruby Hall Clinic, Department of Medicine and Neurology, 40 Sassoon Road, Pune 411 001, India.

Received 7 February 1986 and in revised form 18 March 1987. Accepted 26 March 1987 mon and in our experience with over 2000 cases of organophosphate poisoning we have seen this on only three occasions, each time after ingestion of Dichlorovos. ${ }^{4}$ We report here our electrophysiological studies during the hospital admission for acute organophosphate poisoning.

\section{Materials and methods}

The patients reported here were admitted for acute organophosphate poisoning, usually ingested for suicidal purposes, to the Sassoon Hospital or Ruby Hall Clinic, Pune. They were treated as usual with atropine and pyridine2 aldoxime methiodide (2 PAM). In the early stages 2-PAM was not easily available in India and some cases received only atropine. In the original series of 200 cases $^{2} 42$ developed Type II paralysis and 17 died. The nerve conduction studies reported here include cases from that series and several studied subsequently. A total of 66 cases including 21 cases who had no clear weakness were studied in detail. Nerve conduction was studied using standard techniques and recording from surface electrodes on the abductor digiti minimi for the ulnar nerve and extensor digitorium brevis for the lateral popliteal nerve. The organophosphates chiefly used in these cases were diazinon, malathion, fenthion and sumithion. The frequency of the neurological signs here mentioned and the time course of the paralysis (onset and duration) vary with the drug used but the clinical signs seen were similar ${ }^{5}$ and all the organophosphate insecticides are studied together in this series. The initial studies of these cases were reported at the Second International Congress on Muscle Diseases in Newcastle and has been published as an abstract. 
Table 1 Paralytic signs in organophosphate poisoning: total paralitic cases:- 101 in 350 cases

Inability to lift neck

Inability to sit up.

Ophthalmoparesis

Slow eye movement

Facial weakness

Swallowing difficulty

Limb weakness proximal more than distal

Arellexia

Respiratory paralysis

Death

\section{Observations}

In two separate series of 200 cases and 150 cases respectively Type II paralysis signs were noted in a total of 101 cases $(49 \%)$. Table 1 lists the signs. Cases with only three or less of the signs listed were considered mild. Those with 4-6 signs were considered moderately affected and those with more than six signs were considered severe.

The nerve conduction velocities in the ulnar and lateral popliteal nerves are shown in figs 1 and 2 . Though the figs show that the mean velocities were least in the severely affected and serially better in the moderate, mild and no deficit groups, the differences are not significant. Moreover, it is important to note that the slowest velocities noted were $39 \mathrm{~m} / \mathrm{s}$ in the lateral popliteal and $47 \mathrm{~m} / \mathrm{s}$ in the ulnar nerve and

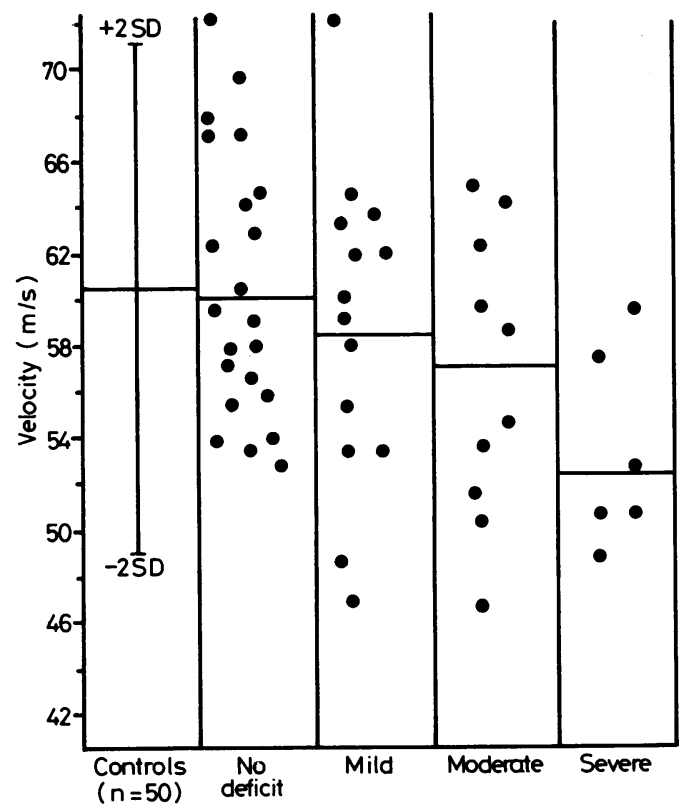

Fig 1 Motor nerve conduction velocity in ulnar nerve.

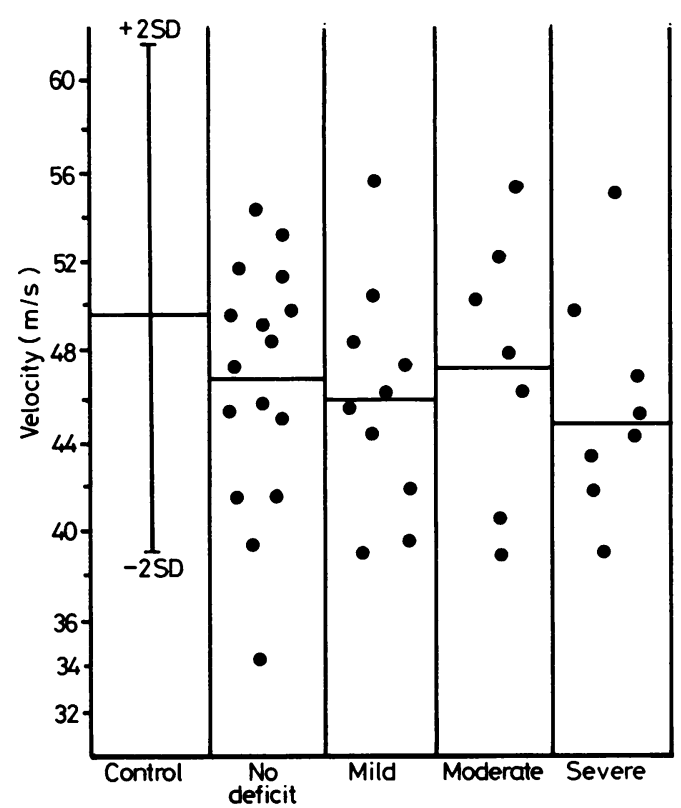

Fig 2 Motor nerve conduction velocities in the lateral popliteal nerve.

only six readings in the entire series were actually a little outside the range of normal for our laboratory. Suffice to say that even in extremis with the patients on a respirator, with minimal limb movement nerve conduction velocities were invariably over $45 \mathrm{~m} / \mathrm{s}$ in the ulnar and $38 \mathrm{~m} / \mathrm{s}$ in the lateral popliteal nerve. Figure 3 shows distal latencies in these cases. Again though these were a little more in the severely affected, there was no case with distal latency outside the range of normal in our laboratory.

Decrement was looked for in cases with weakness and in those without. Tests were done stimulating the ulnar nerve at the wrist and recording from the abductor digiti minimi. Only two cases (who went into respiratory paralysis 24 hours later) showed decrement at $3 \mathrm{~Hz}$. At $10 \mathrm{~Hz}$ only four cases showed decrement. The two cases with decrement at $3 \mathrm{~Hz}$ and four cases with decrement at $10 \mathrm{~Hz}$ were repeated at $30 \mathrm{~Hz}$ and also showed decrement at this rate. Of 18 cases with no deficit seven showed decrement at $30 \mathrm{~Hz}$. Decrement at $30 \mathrm{~Hz}$ was noted in 12 of 19 with mild deficit, three of seven with moderate deficit, and seven of seven with severe deficit. Figure 4 shows one case showing decrement at $30 \mathrm{~Hz}$. In eight cases the decrement tests was repeated more than once after the onset of paralysis. We found that significant decrement may last for 4-11 days after onset of paralysis.

The amplitudes of the compound action potential were also studied. In the early part of the study the 


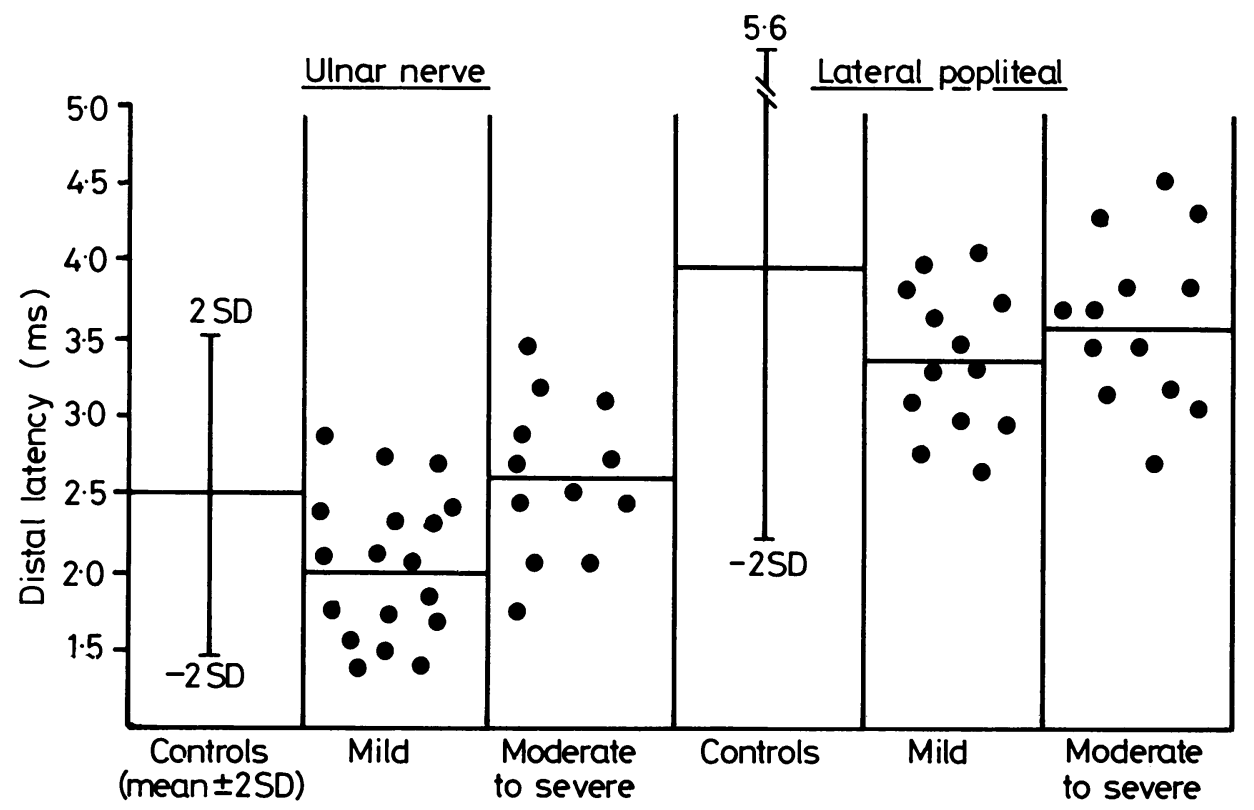

Fig 3 Distal latencies in ulnar and lateral popliteal.

action potentials were measured with both electrodes on the muscle belly. The amplitude we measured was clearly reduced to a mean of $60 \%$ of our control series. In 17 cases we have measured the amplitude with the standard belly tendon electrode placement. Figure 5 shows these results and shows that the amplitude tended to be lower in the more severely affected cases and was below the lower limit of control (mean-2SD) in several.

A repetitive type of muscle action potential to a single stimulation was noted often (fig 6). The addi- tional peaks flattened out on repetitive stimuli. The $\frac{0}{\mathbb{D}} \stackrel{+}{\mathrm{N}}$ response on repeated stimuli is the characteristic of $\frac{\rho}{\mathrm{D}}$ 윽 repetitive activity ${ }^{67}$ and is the method by which it is recognised. When looking for it specifically repetitive activity was noted in precisely $60 \%$ of the cases but was seen in all the cases with clinical signs. We believed at one time that decrement may be seen in cases which did not show repetitive activity. Figure 7 is from one such case classified at one time as showing decrement and not showing repetitive activity. After study of the work of LeQuesne et al $^{7}$ it is clear in fact

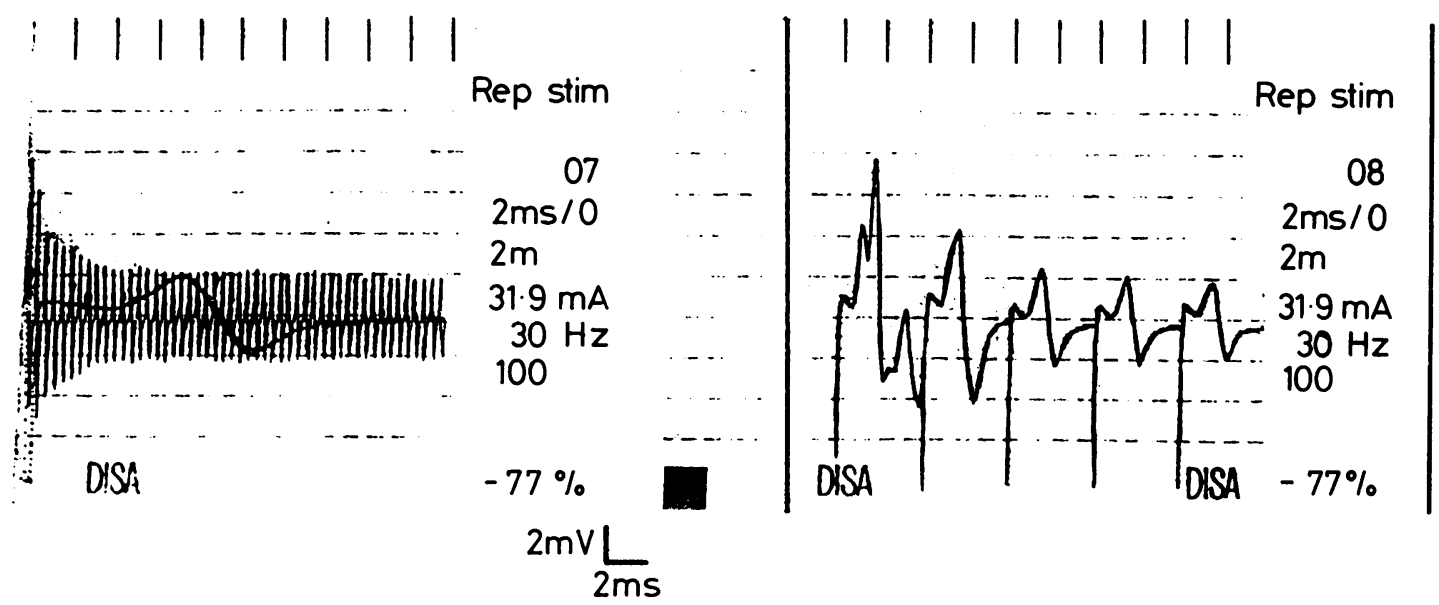

Fig 4 Decrement at $30 \mathrm{~Hz}$ in a case showing moderate neurological deficit. Decrement $\mathrm{S1-S5}$ is $-77 \%$. 


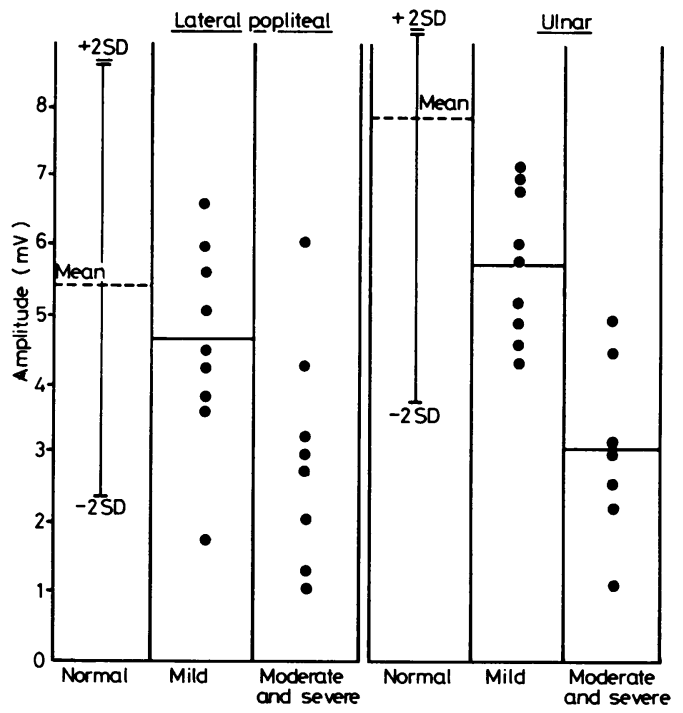

Fig 5 Amplitude of compound action potentials in ulnar and lateral popliteal nerves.

that the first complexes show repetitive activity which disappears in the later complexes.

\section{CORRELATION OF SERUM CHOLINESTERASE WITH} CLINICAL AND ELECTROPHYSIOLOGIC DATA

On the total series of 350 cases cholinesterase (CHE) levels were studied in 121 cases. In these, 50 cases had weakness of varying degree and 40 of these had cholinesterase levels at $10 \%$ or less of the normal. This included all but one with severe weakness. Seven more had serum cholinesterase between $10-20 \%$ of normal. Unfortunately not all these had nerve conduction done but nevertheless the correlation is obvious that neurologic weakness is usually associated with cholinesterase levels less than $20 \%$ of normal. Electrophysiologically such weakness is usually associated with normal nerve conduction velocity and normal distal latency.

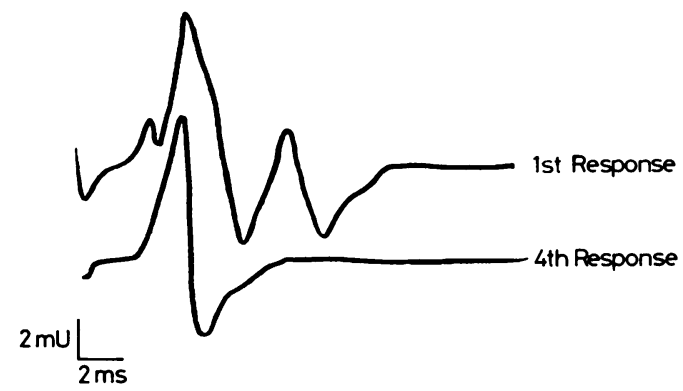

Fig 6 Repetitive activity in organosphosphate poisoning. Note dissappearance of repetitive activity on repeated stimuli.

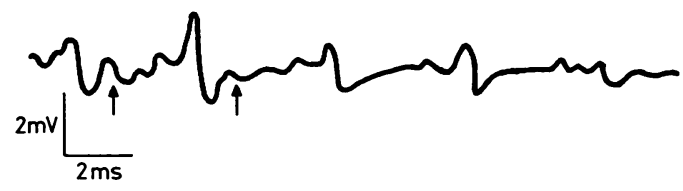

Fig 7 Decrement in organophosphate poisoning at $30 \mathrm{~Hz}$. The first two responses show a small repetitive response (arrows).

In 10 cases cholinesterase levels and electrophysiologic studies were done within hours of each other and serial tests showed that the CHE level was still depressed next day. The results of these cases are set out in table 2 .

\section{Electromyography}

Electromyography was done in 18 cases in Type II paralysis. No case showed fibrillation or positive sharp waves. Units activated appeared mostly normal. Interference pattern was mildly reduced depending on the degree of muscle effort.

\section{Delayed neurotoxicity after anticholinesterase poisoning}

We have now seen three cases who first showed severe cholinergic poisoning then recovered and later developed delayed neurotoxicity. All of these had con-

Table 2 Correlation of cholinesterase levels with clinical and electrophysiological data

\begin{tabular}{|c|c|c|c|c|c|c|c|c|}
\hline \multirow{2}{*}{$\begin{array}{l}\text { Age (yr) } \\
\text { Sex }\end{array}$} & \multirow{2}{*}{$\begin{array}{l}\text { Neurological } \\
\text { deficit }\end{array}$} & \multirow[b]{2}{*}{ CHE level } & \multicolumn{2}{|c|}{ Velocities $(\mathrm{m} / \mathrm{s})$} & \multicolumn{2}{|c|}{ Amplitudes ( $m V)$} & \multirow[b]{2}{*}{ Repetitive act } & \multirow[b]{2}{*}{ Decrement } \\
\hline & & & Ulnar & Lat Popteal & Ulnar & Lat Popteal & & \\
\hline $\begin{array}{l}\text { M30 } \\
\text { (alcoholic) }\end{array}$ & Nil & $<10 \%$ & $66 \cdot 6$ & $49 \cdot 0$ & $6 \cdot 4$ & $2 \cdot 14$ & Nil & Nil \\
\hline $\begin{array}{l}\text { F16 } \\
\text { M26 } \\
\text { F26 } \\
\text { F16 } \\
\text { F34 } \\
\text { F28 } \\
\text { F20 } \\
\text { M21 } \\
\text { F23 }\end{array}$ & $\begin{array}{l}\text { Nil } \\
\text { Nil } \\
\text { Mild } \\
\text { Nil } \\
\text { Mild } \\
\text { Severe } \\
\text { Moderate } \\
\text { Severe } \\
\text { Severe }\end{array}$ & $\begin{aligned}< & 10 \% \\
< & 10 \% \\
& 10-15 \% \\
& 50 \% \\
< & 10 \% \\
< & 10 \% \\
& 10-15 \% \\
< & 5 \% \\
& 15-20 \%\end{aligned}$ & $\begin{array}{l}62 \\
64 \cdot 8 \\
58 \\
69 \cdot 4 \\
73 \cdot 3 \\
52 \cdot 1 \\
51 \cdot 4 \\
60 \cdot 0 \\
47 \cdot 9\end{array}$ & $\begin{array}{l}\text { ND } \\
54 \\
50 \\
50 \cdot 9 \\
56 \cdot 2 \\
45 \cdot 9 \\
54 \cdot 4 \\
55 \cdot 5 \\
44 \cdot 5\end{array}$ & $\begin{array}{l}11 \\
6 \\
6 \cdot 9 \\
8 \cdot 3 \\
4 \cdot 7 \\
2 \cdot 6 \\
3 \cdot 1 \\
3 \cdot 2 \\
1 \cdot 4\end{array}$ & $\begin{array}{l}3 \cdot 6 \\
6 \cdot 0 \\
6 \cdot 5 \\
5 \cdot 2 \\
3 \cdot 1 \\
2 \cdot 9 \\
4 \cdot 3 \\
1 \cdot 4\end{array}$ & $\begin{array}{l}\text { Nil } \\
\text { Nil } \\
\text { Yes } \\
\text { Nil } \\
\text { Yes } \\
\text { Yes } \\
\text { Yes } \\
\text { Yes } \\
\text { Yes }\end{array}$ & $\begin{array}{l}\text { Nil } \\
\text { Nil } \\
\text { Nil } \\
\text { Nil } \\
\text { Nil } \\
\text { Yes } \\
\text { Yes } \\
\text { Yes } \\
\text { Yes }\end{array}$ \\
\hline
\end{tabular}

$\mathrm{ND}=$ not done 
sumed dichlorovos. Unfortunately all three had the episode of anticholinesterase poisoning in an outside hospital. Then, 10-15 days after initial poisoning, the patients started with leg pains and paraesthesia and were admitted with a marked neuropathy. EMG studies showed well marked fibrillation in distal muscles with broad units and reduced interference pattern. Nerve conduction studies at this time showed all the features of a severe axonal degeneration neuropathy with normal sensory conduction. The motor conduction velocities were normal and the motor action potential were very small. For example, in the first case there was no contraction on stimulation of the lateral and medial popliteal nerves and on stimulating the median nerve the amplitude of the action potential was only $0.05 \mathrm{mV}$ to start with and even after 13 weeks of poisoning the action potential was still only $1 \mathrm{mV}$. In comparison the mean amplitude of the action potential in the upper limbs in Type II paralysis was much higher even in severely affected cases and no cases with Type II paralysis had a muscle action potential below $1.4 \mathrm{mV}$ on stimulating the median or ulnar nerve. It is also to be stressed that with the four common organophosphate poisonings we saw (diazinon, sumithion, fenthion and malathion) there was no case of delayed neurotoxicity in over 1000 poisoning episodes.

\section{Discussion}

Four different neurological paralytic disorders have been described following acute organophosphate insecticide poisoning. The initial ones on admission are various muscarinic signs which respond promptly to atropine (Type I paralysis ${ }^{2}$ ). Next to appear is Type II paralysis described here. These signs are seen more frequently with some organophosphates than with others even with similar acute treatment schedules ${ }^{5}$ and last longer with fenthion than with other organophosphates. ${ }^{5}$ However the nature of signs and nerve conduction studies are similar in the different organophosphates and the longer effect is matched with a longer duration of serum cholinesterase depression. The third type of paralytic disease is the one called delayed neurotoxicity. This form is well known after triorthocresyl phosphate poisoning but recently it has been described as a rare event after clinical acute organophosphate anticholinesterase poisoning with some organophosphates (Mipafox, ${ }^{8}$ trichlorofon, ${ }^{9}$ and Methamediphos ${ }^{10}$ ) and is likely to become more frequent as patients survive from severe overdosage. Delayed neurotoxicity is characterised by a severe axonal degeneration type neuropathy and as a result neurophysiological findings are as mentioned quite different with profuse fibrillation, normal sensory conduction, normal or minimally abnormal motor nerve conduction velocities and prolonged distal latencics and low amplitude in the motor action potentials. The amplitudes of the compound action potential were not reported by Senanayake ${ }^{11}$ or Senanayake and Johnson ${ }^{10}$ but we found them to be very low, as expected. The changes are long lasting. The fourth type of paralytic disorder described after organophosphate poisoning is a typical GuillainBarré type syndrome. Fisher ${ }^{12}$ reported one such cases. The patient developed flaccid limb paralysis involving proximal muscles also and subsequently bilatcral facial paralysis. All reflexcs were absent and the CSF showed a protein level of $150 \mathrm{mg} \%$ and normal cells. The nerve conduction showed slow motor conduction velocities consistent with demyelinating ncuropathy. Hc also quoted other possible similar cases. In our experience we too have seen one such case (unpublished) but at the time we had assumed that it was a coincidental Guillain-Barré syndrome during recovery from organophosphate poisoning. The causc-cffect relationship is not established and the occurrence of only one such case in our experience of over 2000 cases of organophosphate poisoning seen over 24 years suggests a coincidental finding.

The EMG and nerve conduction findings in acute organosphosphate poisoning have been reported only rarely, for most physicians see only few cases and the treatment takes priority. We have found four features in these cases. (a) The nerve conduction is usually normal or very mildly slowed, (b) The amplitude of the compound action potentials shows a modest reduction, (c) The repetitive tests show suggestive evidence of neuromuscular junction lesions, and, (d) The musclc responsc to single stimulation shows a repetitive response. This repetitive response disappears on repeated stimulation and this finding is characteristic.

Hinterburchner and Nachmansohn ${ }^{13}$ had contended that "electrical activity invariably stops in any conductive tissue when the enzyme activity (cholinesterase) falls to about $20 \%$ of the critical value". In this study the serum pscudocholinesterase was frequently well below $20 \%$ of initial and, as mentioned before, nerve conduction did not stop and motor conduction velocity was frequently within the normal range though marginally slow in some. Mishra and $\mathrm{Nag}$ (personal communication) also examined 24 subjects with chronic occupational exposure to fenthion. They found CHE levels significantly lowered in these cases compared to controls but nerve conduction velocity was normal. They studicd $\mathrm{F} \& \mathrm{H}$ wave latencies and found delayed $\mathrm{F}$ waves in all and $\mathrm{H}$ waves in eight. We have not studied these parameters in our acutc cases.

The amplitude of the compound muscle action potential on nerve stimulation was often below the normal range especially in the more severely affected 
cases. A similar but less marked finding was reported by Jager et al ${ }^{14}$ in pesticide workers not suffering from acute poisoning. They tested 36 persons working with organophosphate and organochlorine insecticide. In this they mainly recorded the motor response to stimulation of the ulnar nerve and found the mean amplitude of the action potential to be 10.0 $\pm 1.0 \mathrm{mV}$ in the 17 affected cases and $12 \pm 1 \mathrm{mV}$ in controls. In six cases with single acute exposures they found mean amplitude of the muscle action potential after stimulating the ulnar nerve to be $9.0 \mathrm{mV}$. This rose subsequently to $10 \cdot 16 \mathrm{mV}$ with recovery. They also reported two other findings; "repetitive activity" on EMG, which we saw frequently, and a fall in the amplitude of the first action potential evoked after voluntary activity for 10 seconds. The fall was modest, up to a maximum of $12 \%$ and was absent in three. This we did not look for.

Le Quesne and Maxwell ${ }^{7}$ studied the neuromuscular transmission in a healthy human subject given edrophonium bromide. They found a decremental response at $50 \mathrm{~Hz}$ when the subject was tested after $3 \mathrm{mg}$ edrophonium. They also studied the effect of two stimuli $30 \mathrm{~ms}$ apart (equivalent to $33 \mathrm{~Hz}$ ) and found the second was reduced in amp to $70 \%$ of the original. A similar but more modest decrement at $50 \mathrm{~Hz}$ was described by Maxwell et al ${ }^{15}$ in two cases given metrifonate for the treatment of schiztosomiasis. Our repetitive test studies clearly show an unusual abnormality at the neuromuscular junction. The pattern of responses is clearly different from that seen in either myasthenia gravis or the Eaton Lambert syndrome or in botulism. We have seen a similar response in some patients paralysed after snake bite. Jager et $\mathbf{l}^{14}$ did not report the response to repetitive stimuli in their patients but their response after exertion is also suggestive of neuromuscular junction abnormality.

Repetitive activity in organosphosphate poisoning was first described by Harvey et $\mathrm{al}^{16}$ and confirmed by Jager et $a l^{14}$ and Maxwell and LeQuesne. ${ }^{6}$ Drenth et al $^{17}$ reported that $40 \%$ of pesticide workers tested had repetitive activity even though reduction of cholinesterase activity could not be demonstrated. This point has also been stressed by others ${ }^{6} 714$ and therefore repetitive activity is considered the first manifcstation of organophosphatc toxicity. We found repetitive activity in $60 \%$ of cases including all those with neurologic signs but did not note it in others with significantly reduced cholinesterase activity. Similarly Mishra et al (personal communication) studying workers chronically exposed to pesticides found repetitive activity in seven of 24 cases. The cholinesterase activity in the group was significantly lower than controls.

The EMG studies in these cases showed no significant abnormality. In a rapidly reversible condition of acute onset fibrillations or positive sharp waves were not expected and were not seen. We had initially reported ${ }^{2}$ that the nerve histology was mildly abnormal. The slides were later shown in London ( $\mathrm{Dr}$ PK Thomas and Dr $\mathbf{J}$ Cavanagh) and changes were thought to be mostly nonspecific and in scveral could represent post-mortem changes. This is of course in marked contrast to that seen in delayed neurotoxicity where axonal degencration is unequivocal.

Wc interpret our ncurophysiologic findings as demonstrating a reversible lesion at the myoneural junction and perhaps also at the anterior horn cell. The idca of anterior horn cell affection is raised in view of the fall in amplitude of the action potential associated with normal velocity. Such reduction in amplitude is not seen in myasthenia gravis and when seen in botulism or Eaton Lambert syndrome is associated with increment on repetitive testing. The anterior horn cell is of course classically associated with nicotinic acetylcholine receptors and as the lesion in these cases is at these receptors we believe the anterior horn cell should also be involved. On clinical grounds the cranial nerve nuclei were involved as well.

\section{References}

1 Bami HL. Misuse of insecticide in relation to forensic toxicology. Indian J Plant Protection 1981;8:99-104.

2 Wadia RS, Sadagopan C, Amin RB. Sardesai HV. Neurological manifestations of organophosphorous insecticide poisoning. J Neurol Neurosurg Psychiatry 1974;37:841-7.

3 Aldridge WN, Johnson MK. Side effects of organosphosphrous compounds; delayed neurotoxicity. Bulletin of World Health Organisation 1971;44:259-63.

4 Wadia RS, Shinde CS, Vaidya SD. Delayed neurotoxicity after episode of anticholinesterase poisoning with Dichlorovos. Neurology India 1985;33:247-58.

5 Wadia RS, Bhirud RH, Gulwani AV, Amin RB. Neurological manifestations of three organosphosphate poisons. Ind J Med Research 1977;66:460-8.

6 Maxwell IC, Le Quesne PM. Neuromuscular effects of chronic administration of two organosphosphorous insecticides to rats. Neurotoxicology 1982;3:1-10.

7 Le Quesne PM, Maxwell IC. Effects of edrophonium bromide on neuromuscular transmission in a healthy human subject. Neurotoxicity 1981;2:675-85.

8 Bidstrup PL, Bonnell JA, Becker AG. Paralysis following poisoning by a new organophosphate insecticide (Mipafox) report of two cases. $\mathrm{Br} \mathrm{Med} J$ 1953;1:1068-72.

9 Heirons R, Johnson MK. Clinical and toxicological investigations of a case of delayed neurotoxicity in man after acute poisoning by an organophosphrous pesticide. Arch Toxicol 1980;40:279-84.

10 Senanayake N, Johnson MK. Acute polyneuropathy 
after poisoning by a new organophosphate insecticide. $N$ Engl J Med 1982;306:155-7.

11 Senanayake N, Tricresyl phosphate neuropathy in Sri Lanka. A clinical and neurophysiologic study with a three year follow up. J Neurol Neurosurg Psychiatry 1981;44:773-7.

12 Fisher JR. Gullain Barré syndrome following organophosphate poisoning. JAMA 1977;238:1950-1.

13 Hunterbuchner LP, Nachmansohn D. Electrical activity evoked by a specific chemical reaction. Biochem Biophys Acta 1960;40:554-60.

14 Jager KW, Roberts DV, Wilson A. Neuromuscular function in pesticide workers. Brit $J$ Industrial Med 1950;27:273-8.
15 Maxwell IC, Le Quesne PN, Ekue JMK, Biles JE. Effect on neuromuscular transmission of repeated administration of an organophosphrous compound, metrifonate during treatment of children with urinary schiztosomiasis. Neurotoxicology 1981;2:687-701.

16 Harvey AM, Lilienthan JL, Grob D, Jones BF, Talbot SA. The administration of diisoprophylfluorophosphate to man IV. The effects on neuromuscular function in normal subjects and in myasthenia gravis. Bull Johns Hopkins Hosp 1947;81:267-92.

17 Drenth HJ, Ensberge I, Roberts DV. Wilson A. Neuromuscular function in agriculture workers using pesticides. Arch Environ Health 1972;25:395-8. 